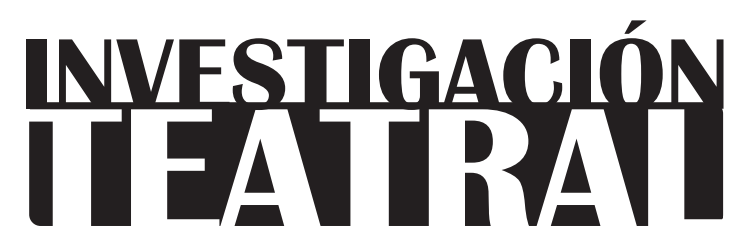

Revista de artes escénicas y performatividad

Vol. 12, Núm. 19

abril-septiembre 2021

Segunda época

ISSN impreso: $1665-8728$

ISSN electrónico: 2594-0953

Universidad Veracruzana

\title{
La ética colaborativa del displazement. La bioética del capitalismo cuestionada por la ética responsiva
}

\author{
Dra. María Teresa Paulín Ríos* \\ Dr. Mario Cantú Toscano**
}

* Universidad Autónoma del Estado de Hidalgo, México. e-mail: teresapaulin@hotmail.com

** Universidad Autónoma de Baja California, México.

e-mail:mario.cantu@uabc.edu.mx

Recibido: 29 de abril de 2020

Aceptado: 12 de noviembre de 2020

Doi: $10.25009 /$ it.v12i19.2673 


\title{
La ética colaborativa del displazement. La bioética del capitalismo cuestionada por la ética responsiva
}

\section{Resumen}

Se propone en este texto una comparación entre la ética de la competencia y la ética de la colaboración, basada en dos formas distintas de entender la naturaleza humana. Las autoras se basan en la filosofía de Paul Ricoeur, Emmanuel Lévinas y Piotr Kropotkin para elaborar una ética de la colaboración, puesta en práctica mediante una disciplina física llamada displazement, la cual puede aportar herramientas filosóficas para actores de la escena actual.

Palabras clave: competencia; colaboración; ética; actores; parkour; Kropotkin.

\section{The Collaborative Ethics of Displazement. The Bioethics of Capitalism Challenged by Responsive Ethics}

\begin{abstract}
This article compares the ethics of competition with the ethics of collaboration, based on two distinct ways of undestanding human nature. The authors base their argument on the philosophical writings of Paul Ricoeur, Emmanuel Lévinas and Piotr Kropotkin, in order to propose an ethics of collaboration. This approach is put into practice through a physical discipline called displazement, which may provide philosophical tools for actors.
\end{abstract}

Keywords: competition; collaboration; ethics; actors; parkour; philosophy. 


\title{
La ética colaborativa del displazement. La bioética del capitalismo cuestionada por la ética responsiva
}

\begin{abstract}
\ 1 proyecto de investigación que incorpora el displazement como recurso escénico nació en 2009, ${ }^{1}$ titulado en su inicio como "El parkour como recurso escénico". En 2015, la investigación cambió de nombre por las razones que se explicarán más adelante y se convirtió en "Displazement como recurso escénico". Existieron diversas etapas y proyectos paralelos que permitieron el desarrollo y la aplicación de la investigación, siendo el más reciente: "Creación transdisciplinaria en espacios alternativos a partir del displazement", financiado por el Programa de Mejoramiento del Profesorado (Promep), que generó diferentes productos. Entre éstos puede citarse el documental El espacio íntimo de Armand Álvarez, ${ }^{2}$ que registra la puesta en escena Altazor o El viaje en paracaídas, texto de Vicente Huidobro bajo la dirección de María Teresa Paulín Ríos.

El propósito de este ensayo es fundamentar las bases éticas (filosóficas) de la técnica teatral denominada displazement en el contexto de un ambiente de competitividad, que no sólo afecta al teatro sino a los sistemas económicos, políticos y culturales de la actualidad en Occidente. Para ello, habremos de describir primero los orígenes de la ética de la competencia, la cual está fundamentada en interpretaciones biológicas de la naturaleza y desplazadas a la naturaleza humana. Y que, por supuesto, tiene mucho que ver con la construcción del pensamiento capitalista y sus repercusiones en las políticas neoliberales.
\end{abstract}

1 Creado por Armand Esteban Álvarez Elías, actor y practicante de parkour y actualmente de displazement. En 2012 se integra a esta investigación María Teresa Paulín Ríos, quien también es practicante de la disciplina. Para conocer mayores detalles sobre la investigación ver Álvarez, "Taller-Laboratorio".

2 El documental El espacio íntimo puede consultarse en línea (ver Álvarez, "Documental”). 
Posteriormente, veremos cómo se ha construido una forma alternativa a esta ética de la competencia, la cual identificamos como una ética de la colaboración. Esta la podemos ver con autores como Paul Ricoeur, Emmanuel Lévinas y Piotr Kropotkin. Mientras que la ética de la competencia interpreta la naturaleza humana a partir de relaciones de dominación, la ética de la colaboración asume al otro como "otro yo", es decir, alguien que, como yo, también puede decir "yo". En el reconocimiento del otro como un sí mismo, surge la necesidad de la responsabilidad.

Y finalmente analizaremos esta otra ética en relación con los valores que implica la práctica del displazement, para confrontar a esta disciplina con el mundo competitivo en el cual nos desarrollamos.

\section{La ética de la competencia}

Comencemos por explicar lo que entendemos por la ética de la competencia. Ésta tiene su origen en el pensamiento capitalista y se ve a sí misma como una bioética, ya que comienza con la biologización de las leyes de la economía. A su vez, la biología toma las leyes de la economía para crear los planteamientos evolucionistas, y de ahí se regresa al campo tanto de la economía como de la sociología. Este proceso comienza a finales del siglo xvin y se consolida durante el siglo xix y principios del xx.

En 1786, Joseph Townsend (citado abajo por Jorge Polo Blanco) publica su Dissertation on the Poor Laws, en la que incluye lo que se conoce como el "teorema de las cabras y los perros":

$\mathrm{Al}$ parecer, en la isla de Robinson Crusoe, frente a las costas de Chile, Juan Fernández dejó unas cuantas cabras para proveerse de carne en futuras visitas. Las cabras allí desembarcadas, que se multiplicaron exponencialmente, acabaron sirviendo de alimento a los corsarios que estaban obstruyendo el comercio de los españoles, los cuales, con el fin de destruirlas, dejaron perros en la isla, y la población de estos últimos también aumentó hasta cierto límite. Se estableció un nuevo balance dentro del conjunto biótico, aseguraba Townsend, un nuevo y espontáneo equilibrio poblacional. "La más débil de ambas especies fue la que primero pagó su deuda con la naturaleza; la más activa y vigorosa preservó la vida". Y, ulteriormente, aplicaría este mismo esquema al interior de los grupos estrictamente antropológicos. "Es la cantidad de alimentos lo que regula el número de la especie humana" (Polo Blanco 96).

La autenticidad de esta anécdota ha sido puesta en duda por diversos teóricos, entre ellos Karl Polanyi (Polo Blanco 97); sin embargo, en su época fue tomada como verda- 
dera. Townsend asegura que el hambre "domará" a los pobres y les enseñará civilidad, pues el hambre es la herramienta para ponerlos a trabajar. Si los pobres tienen hambre, trabajarán y no serán improductivos, ya que las leyes que los protegen hacen que éstos se vuelvan perezosos (ibídem).

De esta forma, Townsend otorga un matiz de legalidad a la explotación, justificándola con dichas observaciones "científicas" sobre el comportamiento "económico" de los animales en la naturaleza (no en estado de domesticación). La cita es bastante elocuente, ya que muestra la clave para el sometimiento del trabajador: el hambre. Algo tan biológico como el hambre es lo que determina el orden social y las relaciones en los medios de producción. Las leyes para combatir la pobreza, es decir, las leyes del Estado que protegen a los pobres, son vistas como un estorbo, ya que no dejan que la naturaleza haga su trabajo. Se trata de una animalización de la sociedad humana.

Por medio de Condorcet, Thomas Robert Malthus conoce el texto de Townsend y se ve influenciado por este para escribir An Essay on the Principle of Population, el cual es publicado en 1798. Su teoría refleja la relación que existe (para él) entre la fecundidad del ser humano y la del suelo. En su ensayo concluye que "sobre una parte de la sociedad deben necesariamente recaer las dificultades de la vida, y estas recaen, por ley natural, sobre sus miembros menos afortunados" (Polo Blanco 104). Así, las leyes de la sociedad son las leyes de la jungla. Completando el trabajo de Malthus, David Ricardo asume que el precio "natural" del trabajo es aquel que le permite al trabajador subsistir en los límites de la escasez (103).

Como es bien sabido, durante el siglo xix comienzan las discusiones sobre la edad de la Tierra, y esto lleva a la formación de hipótesis sobre la evolución. A diferencia de los catastrofistas y de los funcionalistas como Erasmus Darwin y Jean-Baptiste Lamarck, Charles Darwin (nieto de Erasmus) formula su teoría de la evolución basada en la selección natural. En su paradigmático libro publicado en 1859, On the Origin of Species by Means of Natural Selection, el naturalista inglés admite expresamente que su idea de competencia para la adaptación al medio ambiente de las especies está tomado de Malthus. Y dichos principios biológicos, que fueron tomados de la especulación de la "ciencia" económica (que a su vez tenían una pretensión de ciencia biológica), son retomados por otros teóricos como Herbert Spencer, quien traslada la competencia por la supervivencia a modelos éticos y sociológicos (del llamado darwinismo social). Spencer incluso enlaza los postulados de la biología con los de la teología para sus leyes sociológicas: "El mandamiento 'comerás el pan con el sudor de tu frente' es sencillamente una enunciación cristiana de una ley universal de la Naturaleza, y a la que debe la vida su progreso. Por esta ley, una criatura incapaz de bastarse a sí misma debe perecer" (Polo Blanco 104).

A esto nos referimos cuando más arriba mencionamos la animalización de la sociedad humana. Spencer legitima el sistema económico y social de libre empresa y el individualis- 
mo competitivo. Lo que antes era un "privilegio de clase", a partir de Spencer se convierte en una "aristocracia biológica", pues supone que una clase social tiene el "derecho natural" de ser privilegiada, ya que demuestra ser más competente para adaptarse a su medio: son los individuos más fuertes de su medio ambiente.

Algunos otros teóricos, como Alexander Tille, argumentan (siguiendo también a Townsend, Malthus y Spencer) que las políticas ejercidas por un Estado humanitario devienen en medidas contraproducentes, ya que ayudar al más débil contraviene las leyes de la naturaleza. Un Estado humanitario es un Estado que provoca el debilitamiento social. Para William Graham Summer, si se quiere una sociedad mejor preparada, habrá que dejar que opere la ley de la jungla para que sobrevivan los más aptos, y permitir que los menos aptos desaparezcan o se mantengan en los límites de la escasez (Polo Blanco 105). Biología y economía se han unido en una especie de simbiosis (para usar un símil acorde con las ciencias naturales) para legitimar una ética de la competencia, la cual pertenece plenamente al pensamiento capitalista.

Por supuesto que no son las únicas fuentes. También varios sistemas filosóficos, aunque no estén directamente relacionados con el capitalismo, apoyan la ética de la competencia. Unos de estos casos paradigmáticos podría ser la bien conocida "dialéctica del amo y el esclavo" de Hegel. El deseo es deseo porque se desea a sí mismo, es decir, es un querer vivir. Pero en el ser humano, el deseo se presenta de forma que desea los deseos del otro: el sometimiento del otro. De ahí que quien más desea su propia existencia resulta ser el sometido, ya que le importa más vivir que someter. Así, uno se convierte en el amo y el otro en el esclavo. $\mathrm{O}$ también podríamos pensar en el concepto nietzscheano de la voluntad de poder, que crea su propia moralidad. Y esta conducta ética descrita por Nietzsche también legitima, a su manera, la dominación y el sometimiento. O como dice Paul Ricoeur: "La ocasión de la violencia, para no hablar del viraje hacia la violencia, reside en el poder ejercido sobre una voluntad por otra voluntad" (233). No se trata aquí de describir estas filosofías harto conocidas, sino de mostrarlas en el contexto de la construcción de una ética de la competencia. Otra vez: son sólo una muestra, porque el número de ejemplos podría seguir creciendo.

Lo descrito hasta el momento no son solamente constructos teóricos: son realidades socioeconómicas que llegaron a un paroxismo durante el siglo xx y que continúan en el xxi con todas las políticas neoliberales. Los despidos masivos que se vivieron en las últimas décadas del siglo xx (y que continúan en el xxi) obedecen a la ética de la competencia, donde el bienestar de los trabajadores es infravalorado por la competencia entre empresas. Al estilo de la voluntad de poder, las empresas han endiosado el crecimiento y la acumulación del capital en detrimento claro de la dignidad humana. Baste recordar el movimiento de 2011 con el lema "somos el 99\%", que señalaba la exagerada desigualdad de la distribución de la riqueza. La ética de la competencia, bajo el principio de la ley de la jungla y la animalización de la sociedad, se ha colocado en el centro de muchas de las actividades humanas. 
Dado que la ética de la competencia se identifica plenamente con el pensamiento capitalista, es común pensar que lo que se le oponga tendrá que surgir del socialismo/comunismo. No es nuestro deseo identificar la ética de la colaboración con estos pensamientos político-económicos. Es por eso que construimos esto desde otro lado. Y también por eso hemos elegido la palabra colaboración en lugar de cooperación, ya que este último término suele asociarse con el socialismo. Pasemos entonces a explicar lo que entendemos por una ética de colaboración.

\section{La ética de la colaboración}

Ética proviene del griego ethos, que en su traducción más literal significa "comportamiento". El comportamiento evidentemente tiene que ver con cómo se comporta el individuo en sociedad, es decir, frente a otros individuos. Por ello, la ética está ligada a la identidad. Hay dos maneras de observar la identidad: a través del idem y del ipse. Ambos vocablos provienen del latín. El primero significa "lo mismo" y el segundo "sí mismo". Habría entonces que ver la diferencia entre concebir la identidad como un idem o concebirla como un ipse.

Una manera de ver esta diferencia, quizá para una mejor comprensión, es a través de la temporalidad, siguiendo a Juan Ignacio Blanco Ilari. La identidad idem se refiere en primera instancia a la identidad numérica. Que algo sea "lo mismo" significa que es una sola cosa, por ejemplo: "llevo un año usando la misma libreta de apuntes". "Identidad, aquí, significa unicidad, lo contrario de pluralidad" (1). "Lo mismo" también puede significar una semejanza extrema entre dos cosas, una identidad cualitativa: "estos dos textos son idénticos", ambos son una misma cosa. La identidad idem se mantiene en un momento sincrónico. Hasta aquí la identidad se concibe en cuanto a sincronía. ¿Pero qué pasa al revisar la identidad en cuanto a diacronía?

Si tenemos un individuo de cualquier especie, este presenta una mismidad en continuidad: "en el caso de una gran distancia en el tiempo, sugiere que se acuda a otro criterio, que proviene del tercer componente de la noción de identidad, a saber, la continuidad ininterrumpida entre el primero y el último estadio del desarrollo de lo que consideramos el mismo individuo" (Ricoeur 111). Esta continuidad ininterrumpida, en el caso de los individuos que presentan distintos estadios durante su desarrollo biológico y social, la mismidad del idem, se afianza en el carácter. Se dice que una persona es la misma persona entre diferentes etapas de su vida, pues, aunque ha cambiado biológica y mentalmente (experiencias), conserva su identidad: es la misma persona. Y esta argumentación del idem, dice Paul Ricoeur, se centra en la noción de carácter: "El carácter, diría yo hoy, designa el conjunto de disposiciones duraderas en las que reconocemos a una persona. En este aspecto, el carácter 
puede constituir el punto límite que en la problemática del ipse se vuelve indiscernible de la del idem e inclina a no distinguir una de otra" (115).

Para Ricoeur, hablar de carácter presenta una problemática, ya que transforma la diacronía en una sincronía. Pareciera entonces que desde la mismidad del idem no opera ningún cambio en el individuo. Asimilar la identidad con el carácter hace que la diacronía devenga en sincronía. Es como si la persona fuera un retrato, el cual capta el "carácter" del personaje y lo deja inmovilizado. Sin embargo, la identidad ipse se considera en un sentido realmente diacrónico. La persona ya no es un retrato inamovible en su carácter, sino que se vuelve una narración. "El error consiste en suponer que la identidad sólo se debe entender en términos de la mismidad, y que la mismidad es una característica de los objetos y los sucesos" (Blanco Ilari 4).

Podríamos concebir entonces que el idem remite a un "yo"; en cambio, el ispse, a un "sí mismo". El yo es el carácter, el retrato sincrónico; mientras que el sí mismo es una construcción diacrónica del yo en cuanto a que atraviesa por distintos sucesos, es una construcción a través del tiempo y, por lo tanto, una narración. "Cuando Dilthey formaba el concepto de Zusammenhang des Lebens, de conexión de la vida, lo consideraba espontáneamente como equivalente al de historia de una vida" (Ricoeur 139). Por ello, para conocer a una persona, más que enumerar características, se narran historias: la narración también otorga unidad (Blanco Iliari 4).

Para Ricoeur, la persona puede entenderse como un personaje de un relato aunque no sea ficcional porque el sí mismo de la persona son sus experiencias. En el ipse, la persona es la narración de su vida en sí misma ya que comparte la identidad dinámica de la propia historia narrada. "El relato construye la identidad del personaje [la persona como personaje de su historia de vida], que podemos llamar identidad narrativa, al construir la historia narrada. Es la identidad de la historia la que hace la identidad del personaje" (Ricoeur 147). El relato contiene acciones, las cuales pueden entenderse como tareas.

Con esto, Ricoeur hace un cambio en el paradigma de la conciencia. La conciencia había sido entendida por la filosofía como actos que el yo recibe ya sea a través de la razón o de la experiencia; sin embargo, Ricoeur concibe la conciencia como tarea (Marcondes Cesar 200). La conciencia vista de esta forma, como tarea y no como datos recibidos de forma pasiva, implica una conciencia de cuerpo. Ya no aplicará entonces la dicotomía platónico-cartesiana de cuerpo-alma o cuerpo-mente. Al no haber tal dicotomía, se identifica la conciencia con las tareas. El cuerpo y los estados psíquicos son parte del sí mimo: "Es la misma cosa la que pesa sesenta kilos y la que tiene tal o cual pensamiento" (Ricoeur 13). La persona es para sí misma su propio cuerpo (354).

Si para la ontología existencialista lo primero que hay es el ser (no hay esencia, sólo existencia), Ricoeur sostiene que el ser se manifiesta en la carne, la existencia es cuerpo. Pero 
los cuerpos -como bien han apuntado Husserl, Heidegger y Sartre, entre otros- no existen solos en aislamiento. El ser-con heideggeriano indica que todo ser es con otros. El cuerpo se relaciona con otros cuerpos (y objetos, claro está). El yo es un yo mismo, puesto que se construye no como retrato, sino como narración. Se imbrica con las otras narraciones de los otros sí mismos (que para cada quién es un "yo mismo").

[...] las historias vividas de unos se imbrican en las historias de los demás. Episodios enteros de mi vida forman parte de la historia de la vida de los otros, de mis padres, de mis amigos, de mis compañeros de trabajo y de ocio. Lo que hemos dicho antes de las prácticas, de las relaciones de aprendizaje, de cooperación y de competición que aquellas implican, confirma la imbricación de la historia de la vida de cada uno en la historia de muchos otros (163).

Nuevamente, si la identidad idem se refiere al yo, la identidad ipse se refiere al sí mismo. No es igual hablar de yo que de sí mismo. Porque el yo, incluso en la persona gramatical, implica a las otras personas gramaticales: el yo refiere a un tú, un él, ella, nosotros, ustedes, ellos. Pero si consideramos la identidad como sí mismo, esto tiene una propiedad distributiva en el sentido de que ya no hay relaciones de yo-tú o yo-él, sino que cada uno es un sí mismo. Soy "yo mismo", pero dejo de ver al otro como un tú, ellos, etcétera, sino que me relaciono con el otro reconociendo que el otro también es un "yo mismo" de sí. Ello me fuerza a admitir que "el otro no está condenado a ser un extraño, sino que puede convertirse en mi semejante, a saber, alguien que, como yo, dice 'yo'. [...] 'él piensa' significa 'él/ella dice en su interior: yo pienso'. Ésta [sic] es la maravilla de la traslación gnoseológica" (Ricoeur 372).

El yo del idem crea las otras personas gramaticales; el yo mismo del ipse crea que cada quién sea un sí mismo, por ello tiene esta propiedad distributiva. Ver al otro como un tú (distinto a yo) promueve las ya mencionadas relaciones de dominación de la ética competitiva. Mientras que ver que cada uno es un sí mismo obliga a relacionarnos con el otro de una manera distinta.

Ya Heidegger había propuesto una relación de ipseidad del Dasein (el ser humano) con el ser por medio de la Sorge (cura, cuidado). "Pero el cuidado no se capta por ninguna interpretación psicologizadora o sociologizadora, ni en general, por ninguna fenomenología inmediata" (Ricoeur 343). Es por eso que Ricoeur ve que las relaciones entre los sí mismos son relaciones más bien de responsabilidad. "Porque alguien cuenta conmigo, soy responsable de mis acciones ante otro. El término de responsabilidad reúne las dos significaciones: contar con... ser responsable de... Las reúne, añadiéndoles la idea de una respuesta a la pregunta: ‘¿Dónde estás?', planteada por el otro que me solicita” (168). 
Esto nos lleva a otro filósofo: Emmanuel Lévinas, quien ha trabajado esta idea de la responsabilidad. Si bien Ricoeur habla de la persona como un cuerpo (sustentado en la carne) que evade la dicotomía sobre el cuerpo-mente, Lévinas identifica la persona con una parte específica del cuerpo: el rostro. Si bien Lévinas es conocido porque su pensamiento filosófico está enraizado en lo teológico, el filósofo lituano evita construir sobre especulaciones metafísicas como Descartes.

Es bien conocida la prueba de la existencia de Dios de René Descartes: si nosotros, que somos seres imperfectos y finitos, podemos concebir la perfección y lo infinito (cosas que no conocemos mediante la experiencia porque nada de lo que conocemos en el mundo es perfecto e infinito) es porque un ser perfecto e infinito lo puso en nosotros. Ergo: Dios existe. Lévinas no intenta demostrar en ningún momento la existencia de Dios, más bien construye un Dios mundano, ya que, si acaso hay un dios, este se encuentra en el rostro del otro. Lévinas, en lugar de especular sobre la existencia de un ser supremo al que no podemos ver, lo ubica en el plano terreno y carnal, es un dios corporeizado en el rostro de mi semejante. Dios es la humanidad a la que pertenezco y de la que soy responsable.

Nosotros aquí hemos omitido esta parte teológica de Lévinas para que tampoco se confunda esta ética de la colaboración con una ética judeocristiana. La anterior explicación es para dejar en claro que, aunque con fuerte influencia del sionismo, la ética de Lévinas es una ética que atiende al mundo del cuerpo y no de un espíritu o cualquier otra especulación metafísica.

Lévinas, al igual que Ricoeur, identifica a la persona como un cuerpo. Pero a diferencia de éste, se centra en lo que para él es el centro de la identidad: el rostro. "Pero lo que esto significa es que el rostro que yo encuentro en la presencia física del Otro debe expresarse más allá de sí mismo. Son los ojos del Otro los que yo veo y, aun así, viendo los ojos del Otro veo más allá de sus ojos, así como puedo hacerlo con cualquier parte del cuerpo del Otro"3 (Larios 10). Esto recuerda al poema de Antonio Machado: "El ojo que ves no es / ojo porque tú lo veas; / es ojo porque te ve". El rostro del otro no es un rostro porque lo identifiquemos como un tú, es un otro porque te ve, y en ese mirar se encuentra ese “¿dónde estás?" de Paul Ricoeur que pide contar con uno, que pide la responsabilidad. El ojo que mira (de Machado) es el rostro del otro (en Lévinas).

Como ya dijimos, la conciencia había sido vista como datos, información que se recibe sobre la realidad. Husserl entiende la conciencia como intencionalidad, pero Ricoeur ve la

3 But what this means is that the face that I encounter in the physical presence of the Other must express itself beyond itself. It is the eyes of the Other I see, and yet, by looking at the Other's eyes, I see beyond their eyes just as I can do so with any part of the Other's body (traducción realizada por los autores). 
conciencia como tareas. Lévinas asegura que en estas tareas, que se entrecruzan en la relación con los otros (personas y objetos), hay responsabilidad:

$\mathrm{Al}$ extender la mano para acercar una silla, he arrugado la manga de mi chaqueta, he rayado el suelo, he derramado la ceniza de mi cigarro. Al hacer lo que quería hacer, he hecho miles de cosas no deseadas. El acto no ha sido puro, ha dejado huellas. Y, al borrar esas huellas, he dejado otras. [...] Cuando la torpeza del acto se vuelve contra el fin perseguido, nos encontramos de lleno en la tragedia. Para frustrar las funestas predicciones, Layo hará exactamente lo que precisa para que se cumplan. Edipo, al triunfar, construye su propia desgracia. [...] De este modo, somos responsables más allá de nuestras intenciones ${ }^{4}(15)$.

$\mathrm{Al}$ admitir que el otro es un sí mismo, nos hacemos responsables de éste, incluso cuando daña a terceros: "En realidad, soy responsable del otro incluso cuando comete crímenes, incluso cuando otros hombres comenten crímenes. [...] todos los hombres somos responsables unos de otros, y yo más que ninguno. Una vez más estoy citando, como pueden ver, la fórmula de Dostoievski" (Lévinas 133). La relación con el otro no sólo consiste en comprenderle como otro sí mismo, pues una vez que reconocemos que el otro también puede decir "yo", la relación desborda la comprensión: empatizamos. Y la empatía exige esta responsabilidad (17-18).

Esta ética está sustentada en supuestas "leyes biológicas". Así se piensa a sí misma, pues no está consciente de que no son leyes de la naturaleza, sino interpretaciones de la naturaleza. Marshall Sahlins se ha dedicado a analizar las interpretaciones que tenemos de la naturaleza y cómo estas se plasman en los modelos políticos, económicos y sociales. En su libro La ilusión occidental de la naturaleza humana, Sahlins finaliza: "Mi modesta conclusión es que la civilización occidental ha sido construida sobre una idea perversa y equivocada de la naturaleza humana. [...] Sin embargo, probablemente sea cierto que esta idea perversa de la naturaleza humana pone en peligro nuestra existencia" (125). Y agrega que en la evolución humana, además de una selección natural, hay una selección cultural.

Una de las fuentes de donde abreva Sahlins es el geógrafo, naturalista y politólogo ruso Piotr Kropotkin (1842-1921), quien a finales del siglo xix y principios del xx cuestiona severamente las teorías darwinistas de la selección natural (la competencia) y del darwinismo social, en especial a Herbert Spencer, quien admite la ayuda mutua en los animales pero la niega en los seres humanos (Kropotkin XI-XVI).

4 Hemos resaltado la palabra "intenciones" para relacionarla con la intencionalidad de Husserl, es decir, que la conciencia va más allá de la intencionalidad, está también en las acciones, y somos responsables de nuestras acciones más allá de la intencionalidad. 
Kropotkin dedica años de investigación al comportamiento de los animales y la historia económica de la humanidad para demostrar que no es la competencia, sino la ayuda mutua, lo que origina la evolución. Y desprecia tanto la visión naturalista de la biología como la de las políticas económicas y sociales que defienden la tesis de la competencia. Kropotkin hace otra lectura de Darwin, ya que, a su juicio, este sí contempla la colaboración entre las especies como factor en la evolución. La discusión de Kropotkin no es contra Darwin, sino contra los darwinistas, tanto los biólogos como los sociólogos, economistas y filósofos que propagaron la idea de la competencia como el comportamiento "natural" de las especies. Por ello, se dedica durante todo el libro a dar ejemplos de ayuda mutua en distintas especies animales así como en el ser humano en las distintas etapas de su desarrollo social. La ayuda mutua implica desarrollo cultural. Con esto queda quizá más claro lo que Sahlins quiere decir con la evolución a partir de la selección cultural.

¿Cómo se inserta una técnica teatral en el marco de todo esto? ¿Qué sentido tiene hablar de la ética de la colaboración en el marco de la preparación actoral? Hablaremos en específico de la técnica del displazement, pero que muy probablemente puede ser trasladada a otras metodologías. No tanto en el carácter propiamente de la técnica, sino de la ética que se desprende de ésta.

\section{El rompimiento a partir de la estética con el displazement}

Cuando una obra de teatro llega a ser poética ${ }^{5}$ se caracteriza por su originalidad, su capacidad de expresión y la multiplicidad de sentidos que es capaz de generar, entre muchas otras cosas. En México, cada vez más, el teatro se encuentra inscrito en el sistema competitivo a través de los numerosos premios y certámenes que buscan proyectar el trabajo de algunos directores y compañías, generando con ello representatividad y ganancias económicas: los Premios Metropolitanos de Teatro (en la Ciudad de México), los Premios del Público a lo Mejor del Teatro (por la Universidad de Guadalajara), el Festival Internacional de Teatro

5 "[...] la poética (con minúscula) es el conjunto de componentes constitutivos del ente poético en su doble articulación de producción y producto, integrados en el acontecimiento en una unidad material-formal ontológicamente específica, organizados jerárquicamente, por selección y combinación, a través de procedimientos. Además, la poíesis determina su diferencia ontológica respecto de los otros entes de la vida cotidiana a partir de características específicas (entidad metafórica y oximorónica, autonomía, negación radical del ente 'real', violencia contra la naturaleza y artificiosidad, desterritorialización, de-subjetivación y re-subjetivación, puesta en suspenso del criterio de verdad, semiosis ilimitada, despragmatización y repragmatización, instalación de su propio campo axiológico, soberanía)" (Dubatti 39). 
Universitario (organizado por la UNAM), por mencionar algunos. No obstante, la participación en los concursos responde a una serie de parámetros a los cuales la puesta en escena debe alinearse. Por esta razón, muchas de las creaciones no pueden participar en los concursos o tienen que homogeneizar su lenguaje para adaptarse a lo solicitado. Esta adaptación elimina la alteridad y con ello los rasgos que distinguen una creación de la otra, coartando la libertad de expresión de los artistas. La industria también ha explotado al teatro despojándolo de su identidad y haciéndolo consumible y entretenido.

El camino de la rivalidad, por lo tanto, puede aportar bienes materiales y "prestigio", pero nos regresa a la lucha por la existencia a partir del sometimiento al otro, cultivando su alienación y con ello la pérdida de la libertad. En la disciplina teatral no es distinto; destruir el lenguaje del otro equivale a la aniquilación del propio lenguaje, a la destrucción de nuestro universo creativo y con ello a la proliferación de creaciones cuantificables que se repiten continuamente y que generan un teatro complaciente. ${ }^{6}$

En busca de nuevas posibilidades de articular las relaciones entre los seres vivos, de alternativas de convivencia paralelas a la competencia, se generó a principios de los años ochenta una disciplina que promovía la fuerza, el respeto y el coraje como valores éticos: el parkour, fundado por el grupo Yamakasi ${ }^{7}$ en los alrededores de París, Francia. La palabra yamakasi proviene del lingala, un idioma africano utilizado en el noroeste de la República Democrática del Congo, y significa "cuerpo fuerte, mente fuerte, espíritu fuerte".

6 Jorge Dubatti clasifica los tipos de teatro basándose en cómo la micropolítica generada en el espectáculo se enfrenta o se corresponde con el pensamiento hegemónico de una macropolítica. Así el teatro de la complacencia es el que coincide con el pensamiento hegemónico; el de la compensación hace una ligera crítica, pero termina alineándose con éste; el de la confrontación cuestiona al pensamiento hegemónico, pero no ofrece soluciones, al menos no explícitas; y el teatro beligerante es el que se enfrenta directamente al pensamiento hegemónico y sí ofrece soluciones, pues tiene aspiraciones a convertirse en pensamiento hegemónico. Esto se puede ver en Dubatti, Jorge. Filosofía del teatro I. Convivio, experiencia, subjetividad. Buenos Aires: Autel, 2007, pp. 163-164.

7 Conformado por: Yann Hnautra, Chau Belle, David Belle, Laurent Piemontesi, Sébastien Foucan, Guylain N'Guba Boyeke, Charles Perriere, Malik Dioufy Williams Belle. Para más información puede consultarse en línea el documental Generación Yamakasi (2006, Api Productions / Majestic Force, ver Daniels, "Documental").

El 15, 16 y 17 de noviembre de 2013, Yann Hnautra, Laurent Piemontesi y Châu Belle, fundadores del ADD y del grupo Yamakasi, impartieron un taller titulado "Sprit Yamak" en la ciudad de San Luis Potosí. Durante el último día del evento dieron una conferencia en la cual explicaron los orígenes del ADD y el desarrollo de la disciplina. La información que se presenta fue recopilada de esta conferencia por María Teresa Paulín Ríos, quien más tarde, del 17 al 21 de mayo de 2014, visitó a Laurent Piemontesi, en su casa de Milán. Otra parte de la información con relación a la historia de este grupo proviene de largas conversaciones que sostuvieron durante esa estancia en Italia. 
Los Yamakasi denominaron a la disciplina "Art du déplacement" (ADD) y siguieron trabajando como una gran familia alrededor del mundo; incluso después de que dos de los integrantes ${ }^{9}$ tuvieron diferencias con el resto del grupo, las cuales tenían su origen en el objetivo de la disciplina. Fueron ellos quienes decidieron separarse y llamarla parkour, ${ }^{10}$ inspirados en los recorridos desarrollados por la milicia a partir del método natural de George Hebert. De esta manera nació el grupo Traceurs, ${ }^{11}$ al que se integraron nuevos miembros y se difundió la denominación parkour, como la gran mayoría de personas la conoce, para nombrar a la disciplina.

Los Yamakasi, por su parte, llamaron la atención de algunos directores de cine y llegaron incluso a realizar películas como Yamakasi: Les samouraïs de temps modernes (Yamakasi: Los samuráis de los tiempos modernos) de Ariel Zeitoun y Julien Seri, con un guion de Luc Besson, y su secuela Yamakasi: Les fils du vent (Yamakasi: Los hijos del viento).

Así como el capitalismo absorbió algunos conceptos biológicos y las actividades artísticas, hizo lo mismo con el parkour. Algunos años después de haber salido a la luz, marcas como Red Bull comenzaron a realizar competencias de parkour promoviendo su producto. De manera paulatina, la disciplina se fue transformando en un deporte, situación que la Federación Internacional de Gimnasia (FIG) aprovechó para absorberla, junto con sus diferentes nombres e incluyéndola como su octava disciplina. La FIG generó lineamientos que nada tienen que ver con los principios y valores originales que los Yamakasi plantearon en su inicio, y comenzó a cobrar cuotas a los gimnasios que quisieran afiliarse. En otras palabras, la FIG vio en el parkour un negocio que podía restituirle la popularidad que estaba perdiendo y rompió los principios originales de la disciplina; aplicando su propia moralidad, para retomar el concepto nietzscheano de voluntad de poder que mencionamos anteriormente.

Previendo esta situación y buscando salvaguardar y continuar el desarrollo de los valores auténticos de la disciplina, que se perdían rápidamente, así como evitar la competencia, un grupo de personas ${ }^{12}$ crearon en 2015, a partir del ADD o parkour, el displazement: una disciplina recreativa que explora las posibilidades de desplazamiento en el entorno, mientras resuelve dificultades a través de los recursos físicos disponibles. Su metodología se basa en un sistema cooperativo, que busca el autoconocimiento y el crecimiento personal. La idea es proporcionar una alternativa de educación física, mental y espiritual, a

\footnotetext{
9 David Belle y Sébastien Foucan.

10 La palabra proviene del francés parcours, en español "recorrido".

11 Vocablo en francés que significa "trazadores".

12 Armand Álvarez, María Teresa Paulín y Soxacen Rodríguez.
} 
través de un sistema educativo sustentado en una filosofía en movimiento. La disciplina se articula en dos pilares: la actividad física y la filosófica.

En primer lugar, la concordancia con la ética de la colaboración es que el displazement no conoce la dicotomía platónico-cartesiana de cuerpo-alma o cuerpo-mente: su base ontológica, como en Ricoeur y Lévinas, está en la carne: el cuerpo. La actividad mental y la actividad física son una sola cosa; por ello, la conciencia también está vista como una tarea tanto en el sentido de Ricoeur como en el de Stanislavski. A continuación la descripción de esta metodología y práctica.

La actividad física incluye ocho capacidades: caminar, desplazamiento con dos puntos de apoyo; correr, desplazamiento con velocidad; trepar, desplazamiento arriba-abajo; saltar, desplazamiento aéreo de un punto a otro; caer, aterrizaje; cuadrupedia, desplazamiento en cuatro puntos de apoyo; estabilizar, rango de control en una posición fija o desplazamiento, y balanceo, un movimiento pendular que realiza un cuerpo a partir de una articulación.

La filosofía, por su parte, se compone de cuatro valores: el respeto, que promueve la idea de que cada persona tiene valor por sí misma, lo cual rompe con la comparación entre dos practicantes, permitiéndoles concentrarse en su desarrollo personal; la voluntad, misma que consiste en cultivar la capacidad de hacer algo por iniciativa propia; la valentía, que reside en el reconocimiento pleno de las capacidades y restricciones del ejecutante, es decir, en su posibilidad de evaluar si el riesgo es o no aceptable antes de ejecutar un desplazamiento; finalmente la creatividad, la cual consiste en la capacidad de generar y resolver problemas, y con ello estimular la imaginación del practicante.

No obstante, como mencionamos anteriormente, lo que más nos interesa de esta disciplina es su filosofía en movimiento, pues tanto las capacidades como los valores se entretejen para conformar un ambiente de confianza y equidad, ya que al no existir competencia los practicantes quedan absueltos de compararse entre ellos, así como de la "competencia consigo mismos". En otras palabras, se liberan de la presión y las expectativas, abriendo el sitio para un diálogo más sincero durante la exploración de los espacios y de sus movimientos. Dicho de otra forma, en coincidencia con Ricoeur, la filosofía del displazement es una ética del ipse, del sí mismo.

El respeto surge de manera natural, pues a través del movimiento, de la ejecución de un salto, por ejemplo, el practicante comprende que necesita una concentración total que le permita no errar la distancia o la fuerza y evitar un accidente. Promueve una responsabilidad de las acciones como lo señalan tanto Ricoeur como Lévinas. De esta manera, comienza a generar un ambiente de trabajo, tanto para él como para sus compañeros, pues reconoce, como diría Lévinas, "el rostro del otro", tanto en su exposición como en el enorme esfuerzo que realiza para poder llevar a cabo el desplazamiento. El principio de respe- 
to de esta disciplina se sustenta entonces en el ipse, en ese ver al otro en "sí mismo" que comprende hacerse responsable y empatizar con él.

Se construye en unión y a través de la empatía una dinámica inclusiva, amorosa, puesto que cada practicante se encuentra mientras observa los movimientos del otro y a través de los objetivos que construye con él. Durante la acción, la percepción cambia, el acontecimiento los reúne, los vincula. La búsqueda de los practicantes no es la de someter al otro, sino la de liberarlo y, con ello, la de liberarse a sí mismo a través del movimiento. Byung Chul-Han señala en La expulsión de lo distinto: "Conocimiento es redención. El conocimiento entabla una referencia amorosa con su objeto en cuanto distinto. En eso se diferencia de la mera noticia o información, que carece por completo de la dimensión de alteridad" (14-15).

No obstante, para llegar al autoconocimiento y a la redención, existe primero una voluntad de transgresión, de ir más allá de los propios límites y el confort. Esta transgresión es voluntaria, de no ser así carecería de sentido. No se le exige o presiona al practicante, pues toma las decisiones de manera voluntaria, con paciencia y consciencia de sus capacidades. Cada quién a su tiempo va articulando un proceso que no es lineal, tomando como guía los ejercicios que comparte el coach. ${ }^{13}$ Por esta razón, esta disciplina solicita valentía, pues no cualquiera está dispuesto a correr el riesgo necesario que implica el crecimiento. No hablamos únicamente a nivel físico, sino, sobre todo, a nivel interior, aunque en realidad no se puede desvincular una cosa de la otra. Es fundamental señalar que al hablar de disciplina nos referimos a un método, que permite encaminar la actividad a la búsqueda de los objetivos; no olvidemos que las actividades recreativas y los juegos también necesitan de una serie de pasos ordenados para poder articularse, aunque muchas veces estos pasos puedan modificarse en función del objetivo.

Entre las enseñanzas que construye el displazement está la capacidad de reconocer si un riesgo es o no es aceptable. La valentía que promueve la disciplina opera de la mano con la capacidad de análisis de los practicantes, pues no se trata de realizar un salto al primer impulso. Por el contrario, primero se debe reflexionar en las posibilidades y capacidades que se poseen para realizar o no el salto, o cualquier otro desplazamiento, pues no se busca impresionar a nadie y mucho menos trabajar con adrenalina, sino con paciencia y concentración para evitar lesiones y accidentes. La valentía no es entendida como un acto heroico, sino como un acto de responsabilidad (el cuidado propio y del otro). Es por esta razón que lo primero que se les recomienda a los practicantes es que comiencen a dialogar con sus miedos, para identificarlos y asumirlos.

13 En este caso la definición de coach no se traduce como "entrenador", sino como "guía de la actividad", pues no se trata de un entrenamiento, sino de la práctica de una disciplina. 
El miedo estará presente de manera continua durante la práctica, pues es un indicador; pertenece al sistema defensivo del ser humano y nos advierte sobre la posible existencia de un peligro. Por lo tanto, es importante no evadirlo o suprimirlo, sino aprender a trabajar con él para evitar accidentes y hacerse responsable de la propia práctica. La valentía entonces radica en la capacidad de trabajar con el miedo y admitir cuando el riesgo es o no aceptable. Se cultiva entonces la valentía desde la visión aristotélica que afirma que no es posible llamar valiente a aquel que no siente miedo. El filósofo José Antonio Marina propone, incluso, la existencia de una ética de la valentía, planteándola como un valor que debe ser utilizado para un bien y la relaciona además con el siguiente de los valores que promueve el displazement, la creatividad:

La valentía es una virtud creadora, la que proporciona la energía y la habilidad para realizar lo valioso. Ésta es la definición estricta de creación: hacer que algo valioso que no existía, exista por mí. El creador está dispuesto a mantener su acción a pesar de la dificultad o el esfuerzo. Y eso es valentía (Marina, Anatomía 243).

La creatividad, por su parte, es un valor que se construye en cada momento de la práctica y actúa junto con la voluntad y la inteligencia, pues los practicantes resignifican los espacios a través del uso del mobiliario o las construcciones urbanas: el ejecutante de displazement debe articular continuamente los movimientos y las distintas maneras de ponerlos en práctica. En otras palabras, genera diferentes problemas y sus posibles soluciones. Por esta razón, pensamos que la inteligencia del practicante se asemeja a lo que José Antonio Marina define como inteligencia creadora:

[...] la que permite, mediante una poderosa conjunción de tenacidad, retórica interior, memoria, razonamiento, invención de fines, imaginación -en una palabra, gracias al juego libre de las facultades-, que veamos una salida cuando todos los indicios muestran que no la hay. Inteligencia es saber pensar, pero también tener ganas o valor para ponerse a ello (Marina, Teoría 16-17).

Como podemos observar, todos los valores entran en juego durante la práctica y se sostienen unos a otros, generando una técnica. No obstante, es la creatividad aquella que evidencia la relación del displazement con el teatro, pues al no existir competencia es más sencillo que pueda crearse una poética. En otras palabras, tanto los objetivos del displazement como los de una puesta en escena se enfocan en la creación de un problema y su resolución, sobre todo en el terreno actoral, a través de la selección y puesta en práctica de una serie de elementos y sus múltiples procedimientos. No es una conducta natural la que 
se precisa del creador/practicante, sino la construcción de un universo que requiere de una técnica concreta para su articulación:

[...] cada espectáculo está exigiendo una técnica correspondiente. Poética y técnica van de la mano, se definen mutuamente. Puede tratarse de una técnica muy cerrada (como en algunos géneros hipercodificados: la ópera tradicional, la danza clásica, el teatro negro, el teatro realista, el sainete, el títere de retablo, etcétera) o más abierta (la danza contemporánea, el teatro experimental, el teatro no ilusionista, el teatro "tosco" popular, etcétera), e incluso heteróclita, híbrida, múltiple, de mezclas contrastantes, de disolución, inclasificable (Dubatti 141).

Si bien la actividad física, incluida la técnica, puede ser enormemente aprovechada por los artistas escénicos, lo que más nos compete en este artículo es la filosofía en movimiento que promueve el displazement a través de los valores antes expuestos, mismos que entran en juego durante la práctica de la disciplina por medio del movimiento. En general, el proceso del practicante es el mismo que lleva a cabo el actor. Como hemos visto anteriormente, ambos precisan de una técnica, del uso de una imaginación poderosa, pues antes de realizar un desplazamiento, el practicante de displazement debe generar la imagen del movimiento a ejecutar. Tanto el practicante como el actor requieren, además, de un acto de voluntad que los lleve a la transgresión de su ser; es decir, a ir más allá de su lugar común, de su inmediatez, consiguiendo con ello la libertad a través del rompimiento de sus límites. No obstante, cabe señalar que la práctica del displazement puede tornarse más violenta debido a que el proceso del ejecutante es más sintético y un accidente puede ser mucho más grave que una mala actuación.

La disciplina es generosa y amable, casi cualquier persona puede practicarla, pues no existen niveles o medidas para quienes la realizan. Esto es parte de su filosof ía: todos son bienvenidos a trabajar con sus capacidades y posibilidades. Es por ello que los practicantes se adaptan a sus compañeros y aprenden a construir en grupo de manera colaborativa. Gran cantidad de ejercicios se comienzan en unión y se terminan de la misma manera, en ocasiones aquellos que concluyen primero buscan a los que aún no lo hacen para acompañarlos. Nadie es más o menos por su condición, todos son diferentes y aportan a la práctica, aplicando el ser-con heideggeriano que indica que todo ser es con otros. Gracias al trabajo a partir de esta filosofía, los practicantes van desarrollando empatía, observan y asumen tanto las capacidades como las incapacidades de sus compañeros, construyendo a partir de las mismas. Escuchar al otro y sumarse a su propuesta se vuelve necesario; la competencia no tiene lugar, pues el objetivo no es ganar o ser mejor que el otro, sino crear nuevas posibilidades de estar y observar el mundo a través del movimiento. Como podemos ver, esta 
práctica comparte algunos objetivos con la actividad del actor, pues fácilmente viene a la mente la idea del "sí mágico" stanislavskiano que suma y no divide.

Por ello, el displazement como recurso escénico adquiere sentido en la actividad del actor. A través de su ejercicio, este último comprende y asimila tanto la ética de la disciplina como la manera de ponerla en práctica en su desarrollo profesional. En otras palabras, displazement puede servir como una herramienta de triangulación del conocimiento que descubre valores esenciales como el respeto, la voluntad, la valentía y la creatividad, mismos que operan en la construcción de un mundo más amable: "La hospitalidad es la máxima expresión de una razón universal que ha tomado consciencia de sí misma. La razón no ejerce un poder homogeneizador. Gracias a su amabilidad está en condiciones de reconocer al otro en su alteridad y de darle la bienvenida. Amabilidad significa libertad" (Han 33-34).

El teatro, por su parte, ofrece al espectador nuevas perspectivas del mundo, la posibilidad de conocer otros universos y caminos; su actividad se basa en actos generosos, aunque nos muestren la violencia que impera en la humanidad. Comprender al otro implica extender la mirada para encontrarse en su posición. Si los artistas entienden cómo modificar sus prácticas competitivas entre colegas, asumen sus límites y capacidades, y enfocan su energía en la creación a partir de sus particularidades, nuevos lenguajes podrán emerger.

El displazement como recurso escénico contribuye a la liberación del artista a partir de la revelación de la alteridad, ya que puede mostrarle al practicante, a través de la puesta en práctica de la filosofía de esta disciplina, que las diferencias del otro lo vuelven único y que no hace falta competir para conseguir la mejor versión de su ser.

\section{Fuentes consultadas}

Álvarez, Armand. "Documental El espacio íntimo". YouTube, subido por Naranja-Escena, 24 de mayo de 2019, https://www.youtube.com/watch?v=D1TVApEdk_E, consultado el 26 de marzo de 2021.

Álvarez, Armand. “Taller-Laboratorio: Displazement como recurso escénico”. Armand Álvarez, 2015, https://armandalvarez.wixsite.com/taller-laboratorio?fbclid=IwAROzxgoSMG_efHtYsGMKYvAowVR7Dj6LMV07rG4tLb3ca90k8iWVg_iE0BU, consultado el 26 de marzo de 2021.

Blanco Ilari, Juan Ignacio. "Idem-ipse, dos modelos de identidad”. Proyecto Cerebro y Persona (2016-2019), Seminario Persona, mente y cerebro, 20 de octubre de 2016. Universidad Austral, Argentina, https://www.austral.edu.ar/cerebroypersona/wp- content/uploads/2016/05/Juan-Blanco.pdf, consultado el 19 de febrero de 2020. 
Daniels, Mark. "Documental Generación Yamakasi Completo”. YouTube, subido por Loin Du Sol, 7 de enero de 2015, https://www.youtube.com/watch?v=JZY_L13u6WA, consultado el 26 de marzo de 2021.

Dubatti, Jorge. Introducción a los Estudios Teatrales. Ciudad de México: Libros de Godot, 2011.

Han, Byung-Chul. La expulsión de lo distinto. Barcelona: Herder, 2018.

Kropotkin, Pedro. El apoyo mutuo. Saint Louis, Missouri: Dialectis, 2013.

Larios, Joe. "Levinas and the primacy of the human". Ethics and Environment, vol. 24, núm. 2, 2019, pp. 1-22.

Lévinas, Emmanuel. Entre nosotros. Ensayos para pensar en otro. Valencia: Pre-Textos, 2001.

Marcondes Cesar, Constança. "El mismo y el otro. Una perspectiva sobre la noción de persona en Paul Ricoeur". Agora. Papeles de Filosofía, vol. 25, núm. 2, 2006, 197-206.

Marina, José Antonio. Anatomía del miedo. Barcelona: Anagrama, 2011.

Marina, José Antonio. Teoría de la inteligencia creadora. Barcelona: Anagrama, 2012.

Polo Blanco, Jorge. "Economía y biología. La decisiva influencia del naturalismo en la construcción teórica de la Economía Política”. Daimon. Revista Internacional de Filosofía, núm. 69, 2016, pp. 93-108.

Ricoeur, Paul. Sí mismo como otro. México: Siglo xxi, 2003.

Sahlins, Marshall. La ilusión de la naturaleza humana. México: Fondo de Cultura Económica, 2014. 